\title{
The right hand second to fourth digit ratio (2D:4D) and its relationship with body composition indicators among young population
}

\author{
Joydeep Majumder, Bhavani S. Bagepally \\ Scientist B, Department of Occupational Physiology \& Ergonomics, National Institute of Occupational Health, (Indian Council of Medical \\ Research), Ahmedabad - 380016, Gujarat, India
}

\section{A B S T R A C T}

Objective: Study examined 2D:4D among young adults with an attempt to explore its relation to body composition indicators and somatotyping in Indian population. Methods: 317 participants (190 women; 19-40 years), were examined for digit lengths, height, weight, skinfold thicknesses at various regions, and circumferences of chest, waist, hip, thigh and calf. Body somatotyping were calculated from measurements. Body composition indicators were compared among gender and whole study group between participants with 2D:4D $<1$ and 2D:4D > 1. Results: Height, weight, arm circumference and BMI were significantly higher among women with 2D:4D $<1$ as compared to 2D:4D $>1$; further mesomorphy enhanced with lowered 2D:4D. 3D scatter plot for percent body fat, waist-hip ratio and 2D:4D showed increased body fat with increase in 2D:4D among men. Positive relation emerged between waist-hip ratio and $2 \mathrm{D}: 4 \mathrm{D}$, revealing significant fat deposition at the waist-hip region among women. Conclusion: Although gender is differentiated based on anthropometric characteristics and 2D:4D, digit ratio may have a modest role in understanding the body composition indicators in terms of association between lower 2D:4D with male type pattern of anthropometric indicators even among young Indian women.

Key words: Endomorphy, Mesomorphy, Ectomorphy, India, Gender difference

\section{INTRODUCTION}

The digit ratio (2D:4D) is the ratio of length of index finger (second digit) to the length of ring finger (fourth digit) which epitomize the prenatal gonadal hormone exposure. This knowledge of the finger length pattern was first reported more than a century back. ${ }^{1}$ It has been widely accepted that lower $2 \mathrm{D}: 4 \mathrm{D}$ is an indicative of higher pre-natal testosterone level than estrogen levels. ${ }^{2,3} \mathrm{It}$ signifies the fact that 2D:4D is sexually dimorphic, as men have a lower second to fourth digit ratio., ${ }^{1,45}$

Several studies worldwide have reported 2D:4D in relation to physical performance, sports, ${ }^{3,6,7}$ as well as on muscle strength., ${ }^{2,8}, \mathrm{~A}$ study with 2D:4D and neck circumference on body composition indicators reported that, men with higher 2D:4D are at greater risk of obesity. ${ }^{10}$ McIntyre et al. measured 2D:4D as a measure of approximating androgenic effects during development and reported high prenatal androgen exposure causes greater deposition of fat on the abdomen. ${ }^{11}$ However, literature report limited studies on the Indian population, ${ }^{12,13}$ mainly concentrating on neurobehavioural aspects. ${ }^{14,15}$

Although literature reports the finding of lower 2D:4D in men than in women, investigation revealing the body composition status of men and women with 2D:4D less than or more than one was not found. Further India, being with diverse ethnicity, earlier literature is limited to examine the 2D:4D and its relation to the anthropometric body composition details. Therefore, the present study attempted to systematically investigate the finger length pattern and body composition indicators in young men and women. 


\section{MATERIALS AND METHODS}

\section{Sample}

Study sample comprised of 317 participants (127 men and 190 women), between the ages of 19-40 years $($ men $=21.9 \pm 2.9$ years; women $=21.7 \pm 2.7$ years $)$. Study participants were recruited with by word-of-mouth advertisement and visiting students to the Institute. The enrolled study participants were undergraduate/graduate course students of various universities from the state of Gujarat, India. Well detailed, written informed consent was sought from all the study participants before enrolling them to the study.

\section{Measurements}

All the participants were initially interviewed in detail to collect socio-demographic details. Further the details of self-informed age and lifestyle habits (dietary, smoking, tobacco, alcohol, and exercise) were recorded in the study specific proforma. All the anthropometric measurements were recorded with bare body and shorts for the menfolks by a trained male researcher. Recording for the women participants were done by a trained female researcher. All the length related measurements were performed for 3 times and the average of three values was considered as the respective measurement. The height was measured on a portable stadiometer with VR high speed counter (Holtain Ltd., Crosswell, Crymych, UK) with sensitivity of $1 \mathrm{~mm}$. Weight was measured on a digital weighing scale with sensitivity of $0.1 \mathrm{~kg}$. Bi-epicondylar breadths of humerus and femur were measured with a bone caliper (UNA \& Co., India) according to standard protocol. ${ }^{16}$ The circumferences of chest, waist, hip, thigh and calf were measured with a non-elastic measuring tape. The skinfold thickness measurements (biceps, triceps, subscapular, suprailiac, supraspinale and medial calf) were measured as per standard protocol with a skinfold caliper (Holtain Ltd., Crosswell, Crymych, UK).${ }^{16}$ For the purpose of $2 \mathrm{D}$ and $4 \mathrm{D}$ length measurement, the right hand impression was traced on a white paper. The line joining the inter-digital web-spaces within the fingers was considered as the base-line of fingers. The distal most part of the finger trace was considered as tip-line of the finger. The $2 \mathrm{D}$ length was measured as the length between the mid-point of base-line of second (index) finger to the midpoint of tip-line of index finger. Similarly, the $4 \mathrm{D}$ length was measured for the ring finger.

\section{Calculated variables from anthropometric measurements}

The three components of somatotype - endomorphy, mesomorphy and ectomorphy were calculated according to Heath-Carter technique. ${ }^{16}$ The following anthropometric parameters: weight; height; triceps, subscapuar, supraspinale and calf skinfolds; humerus and femur breadths; and biceps and calf circumferences were used for determining the somatotypes. The somatotype calculation and analysis was performed on trial version of software from Sweat Technologies. ${ }^{17}$ Various ratios and parameters were calculated according to the standard formulae $e^{18-20}$ as mentioned in the Table 1.

\section{Statistical analysis}

Difference in the observed anthropometric parameters as well as calculated variables from anthropometric parameters between men and women participants was analyzed using two tailed independent sample t test. Anthropometric parameters and calculated variables among men and women participants with respect to 2D:4D (more than 1 and less than one) was also observed with two tailed $t$ test. Distribution of 2D:4D with somatotypes and percent body fat among men and women participants were observed using scatter plots. The statistical significance level of $\mathrm{p}<0.05$ was considered significant. The scatter plots were drawn with fitted lines for estimated means with marginal box plots between body composition indicators and 2D:4D. The Statistical Package for the Social Sciences (SPSS) for Windows Version 16.0 (Chicago, IL, USA) was used for statistical analysis.

\section{RESULTS}

The descriptive statistics of the observed anthropometric parameters and calculated variables are presented in Table 2. There was no gender difference for age $(\mathrm{t}(315)=0.539, \mathrm{p}=0.591)$; hip circumference $(\mathrm{t}(315)=-0.895$, $\mathrm{p}=0.371)$; thigh circumference $(\mathrm{t}(315)=0.011, \mathrm{p}=0.991)$; BMI $(\mathrm{t}(276)=0.036, \mathrm{p}=0.971)$ (Table 2).

\begin{tabular}{|c|c|c|}
\hline Parameter & Formula & Measurements used \\
\hline Body density (BD) [18] & $\begin{array}{l}=1.1599-[0.0717 \\
{ }^{*} \log (\text { Bicep+Tricep+Subscapular+Supra-iliac)] }\end{array}$ & $\begin{array}{l}\text { Biceps, triceps, sub-scapular, suprailiac } \\
\text { skinfolds }(\mathrm{mm})\end{array}$ \\
\hline Percent body fat (\%BF) [18] & $=(495 / \mathrm{BD})-450$ & Body density \\
\hline Waist-Hip ratio (WHR) & $=$ Waist circumference/Hip circumference & Waist circumference $(\mathrm{cm}) \&$ hip circumference $(\mathrm{cm})$ \\
\hline Waist-Height ratio (WHtR) & $=$ Waist circumference/Height & Waist circumference $(\mathrm{cm})$ and height $(\mathrm{cm})$ \\
\hline Body mass index (BMI) & $=\left(\right.$ Body mass $/\left(\right.$ Height $\left.^{2}\right)$ & Height $(\mathrm{m})$, weight $(\mathrm{Kg})$ \\
\hline Body surface area (BSA) [19] & $=(\text { Height })^{0.725 *}($ Weight $){ }^{0.425 * 0.007184}$ & Height $(\mathrm{m})$, weight $(\mathrm{Kg})$ \\
\hline Body adiposity index (BAI) [20] & $=\left((\right.$ Hip circumference $) /\left(\left(\right.\right.$ Height $\left.\left.\left.^{1.5}\right)-18\right)\right)$ & Hip circumference $(\mathrm{cm})$, height $(\mathrm{m})$ \\
\hline
\end{tabular}


Table 3 and Table 4 report the body composition indicators among men and women, respectively with 2D:4D more than one and less than one. Height was significantly higher among men with 2D:4D less than one as compared to $2 \mathrm{D}: 4 \mathrm{D}$ more than one $(\mathrm{p}=0.047)$ as tabulated in Table 2. In case of women, height, weight, arm circumference and BMI were significantly higher with 2D:4D less than one as compared to the rest (Table 3).

On observing the graphical scatter plot of 2D:4D with somatotype values (endomorphy, mesomorphy, and ectomorphy), it is revealed that mesomorphy (muscular robustness) enhanced with lowered 2D:4D (Figure 1b), whereas endomorphic and ectomorphic characteristics remained unvarying among the men (Figure 1a,c). Among women, all the three somatotype characteristics were not following any pattern with the 2D:4D (Figure 1a-c). Percent body fat was found to be inversely related with 2D:4D among men, whereas relative fatness was found increasing, among women with increase in their 2D:4D (Figure 1d).

\begin{tabular}{|c|c|c|c|c|c|}
\hline Parameters & $\begin{array}{c}\text { Men } \\
\text { Mean } \pm S D\end{array}$ & $\begin{array}{c}\text { Women } \\
\text { Mean } \pm S D\end{array}$ & $P$ value & $\begin{array}{c}\text { Mean } \\
\text { difference }\end{array}$ & $\begin{array}{l}95 \% \text { confidence } \\
\text { interval }\end{array}$ \\
\hline Age (years) & $21.85 \pm 2.86$ & $21.68 \pm 2.72$ & 0.59 & 0.171 & -0.46 to 0.80 \\
\hline Height $(\mathrm{cm})$ & $171.00 \pm 6.30$ & $155.18 \pm 6.19$ & $<0.001$ & 15.822 & 14.38 to 17.27 \\
\hline Weight (kg) & $60.97 \pm 8.68$ & $50.99 \pm 11.75$ & $<0.001$ & 9.976 & 7.72 to 12.23 \\
\hline Humerus breadth (cm) & $6.77 \pm 0.33$ & $5.83 \pm 0.38$ & $<0.001$ & 0.934 & 0.85 to 1.02 \\
\hline Femur breadth $(\mathrm{cm})$ & $9.00 \pm 0.44$ & $8.09 \pm 0.71$ & $<0.001$ & 0.909 & 0.78 to 1.04 \\
\hline Arm circumference $(\mathrm{cm})$ & $27.54 \pm 2.25$ & $23.82 \pm 3.26$ & $<0.001$ & 3.719 & 3.11 to 4.33 \\
\hline Chest circumference $(\mathrm{cm})$ & $86.10 \pm 5.97$ & $78.71 \pm 9.01$ & $<0.001$ & 7.388 & 5.74 to 9.04 \\
\hline Waist circumference $(\mathrm{cm})$ & $74.62 \pm 7.84$ & $66.28 \pm 10.02$ & $<0.001$ & 8.336 & 6.36 to 10.31 \\
\hline Hip circumference $(\mathrm{cm})$ & $89.15 \pm 6.84$ & $90.01 \pm 10.20$ & 0.371 & -0.855 & -2.74 to 1.03 \\
\hline Thigh circumference $(\mathrm{cm})$ & $52.17 \pm 4.95$ & $52.16 \pm 7.14$ & 0.991 & 0.008 & -1.33 to 1.34 \\
\hline Calf circumference $(\mathrm{cm})$ & $32.86 \pm 2.68$ & $30.09 \pm 4.73$ & $<0.001$ & 2.773 & 1.95 to 3.59 \\
\hline Biceps skinfold (mm) & $4.55 \pm 1.82$ & $8.83 \pm 3.49$ & $<0.001$ & -4.275 & -4.87 to -3.69 \\
\hline Triceps skinfold (mm) & $9.62 \pm 4.05$ & $13.94 \pm 4.56$ & $<0.001$ & -4.322 & -5.30 to -3.34 \\
\hline Subscapular skinfold (mm) & $11.06 \pm 3.68$ & $11.70 \pm 3.73$ & 0.133 & -0.639 & -1.47 to 0.20 \\
\hline Suprailiac skinfold (mm) & $9.77 \pm 5.35$ & $12.70 \pm 4.72$ & $<0.001$ & -2.933 & -4.05 to -1.81 \\
\hline Supraspinale skinfold (mm) & $12.78 \pm 5.70$ & $13.62 \pm 4.55$ & 0.162 & -0.846 & -2.03 to 0.34 \\
\hline Medical calf skinfold (mm) & $9.61 \pm 4.01$ & $14.35 \pm 3.96$ & $<0.001$ & -4.738 & -5.63 to -3.84 \\
\hline 2D: 4D & $0.98 \pm 0.04$ & $1.00 \pm 0.04$ & $<0.001$ & -0.019 & -0.03 to -0.01 \\
\hline Endomorphy & $3.32 \pm 1.18$ & $4.29 \pm 0.93$ & $<0.001$ & -0.966 & -1.22 to -0.72 \\
\hline Mesomorphy & $3.43 \pm 1.03$ & $2.80 \pm 1.72$ & $<0.001$ & 0.625 & 0.31 to 0.94 \\
\hline Ectomorphy & $3.38 \pm 1.38$ & $2.68 \pm 1.54$ & $<0.001$ & 0.696 & 0.35 to 1.04 \\
\hline Percent body fat (\%) & $20.94 \pm 4.96$ & $25.55 \pm 3.71$ & $<0.001$ & -4.606 & -5.62 to -3.59 \\
\hline Waist-hip-ratio & $0.84 \pm 0.06$ & $0.74 \pm 0.08$ & $<0.001$ & 0.100 & 0.08 to 0.12 \\
\hline Waist-height-ratio & $0.44 \pm 0.05$ & $0.42 \pm 0.06$ & 0.073 & 0.012 & -0.001 to 0.02 \\
\hline BMI $\left(\mathrm{kg} / \mathrm{m}^{2}\right)$ & $20.77 \pm 2.59$ & $20.76 \pm 4.40$ & 0.971 & 0.015 & -0.79 to 0.82 \\
\hline Body adiposity index & $21.88 \pm 3.24$ & $28.32 \pm 5.33$ & $<0.001$ & -6.436 & -7.43 to -5.45 \\
\hline Body surface area $\left(\mathrm{m}^{2}\right)$ & $1.71 \pm 0.12$ & $1.46 \pm 0.16$ & $<0.001$ & 0.246 & 0.21 to 0.28 \\
\hline
\end{tabular}

SD: Standard deviation

\begin{tabular}{|c|c|c|c|c|c|c|}
\hline & \multicolumn{2}{|c|}{$2 D: 4 D>1$} & \multicolumn{2}{|c|}{$2 D: 4 D<1$} & \multirow[t]{2}{*}{ p value } & \multirow{2}{*}{$\begin{array}{l}95 \% \text { confidence } \\
\text { interval }\end{array}$} \\
\hline & Mean & SD & Mean & SD & & \\
\hline Height (cm) & 169.47 & 5.970 & 171.78 & 6.357 & 0.047 & -4.58 to -0.04 \\
\hline Weight (kg) & 59.53 & 7.480 & 61.70 & 9.183 & NS & -5.16 to 1.03 \\
\hline Arm circumference (cm) & 27.41 & 2.205 & 27.60 & 2.290 & NS & -1.02 to 0.64 \\
\hline Endomorphy & 3.6 & 1.276 & 3.2 & 1.1226 & NS & -1.03 to 0.81 \\
\hline Mesomorphy & 3.5 & 1.065 & 3.4 & 1.0097 & NS & -0.27 to 0.50 \\
\hline Ectomorphy & 3.3 & 1.364 & 3.4 & 1.3966 & NS & -0.63 to 0.39 \\
\hline Percent body fat (\%) & 21.569 & 4.757 & 20.630 & 5.058 & NS & -0.87 to 2.75 \\
\hline Waist-hip-ratio & 0.834 & 0.050 & 0.839 & 0.066 & NS & -0.03 to 0.02 \\
\hline BMI (kg/m²) & 20.733 & 2.514 & 20.790 & 2.645 & NS & -1.01 to 0.89 \\
\hline Body adiposity index & 22.307 & 2.985 & 21.661 & 3.366 & NS & -0.51 to 1.80 \\
\hline
\end{tabular}




\begin{tabular}{|c|c|c|c|c|c|c|}
\hline & \multicolumn{2}{|c|}{ 2D:4D>1 } & \multicolumn{2}{|c|}{$2 \mathrm{D}: 4 \mathrm{D}<1$} & \multirow[t]{2}{*}{$p$ value } & \multirow{2}{*}{$\begin{array}{l}95 \% \text { confidence } \\
\text { interval }\end{array}$} \\
\hline & Mean & SD & Mean & SD & & \\
\hline Height $(\mathrm{cm})$ & 153.80 & 6.132 & 156.39 & 6.019 & 0.007 & -4.44 to -0.73 \\
\hline Weight (kg) & 48.48 & 11.176 & 53.16 & 11.854 & 0.006 & -7.98 to -1.39 \\
\hline Arm circumference (cm) & 23.26 & 3.082 & 24.30 & 3.339 & 0.026 & -1.96 to -0.12 \\
\hline Endomorphy & 4.2 & 0.822 & 4.3 & 1.025 & NS & -0.37 to 0.19 \\
\hline Mesomorphy & 2.6 & 1.602 & 3.0 & 1.795 & NS & -0.99 to 0.04 \\
\hline Ectomorphy & 2.9 & 1.552 & 2.5 & 1.510 & NS & -0.01 to 0.93 \\
\hline Percent body fat (\%) & 25.38 & 3.599 & 25.70 & 3.807 & NS & -1.38 to 0.74 \\
\hline Waist-hip-ratio & 0.74 & 0.092 & 0.74 & 0.068 & NS & -0.02 to 0.02 \\
\hline $\mathrm{BMI}\left(\mathrm{kg} / \mathrm{m}^{2}\right)$ & 20.02 & 4.194 & 21.40 & 4.496 & 0.042 & -2.71 to -0.05 \\
\hline Body adiposity index & 27.9 & 4.992 & 28.68 & 5.620 & NS & -2.41 to 0.83 \\
\hline
\end{tabular}

SD: Standard deviation; NS: Not significant at $p<0.05$

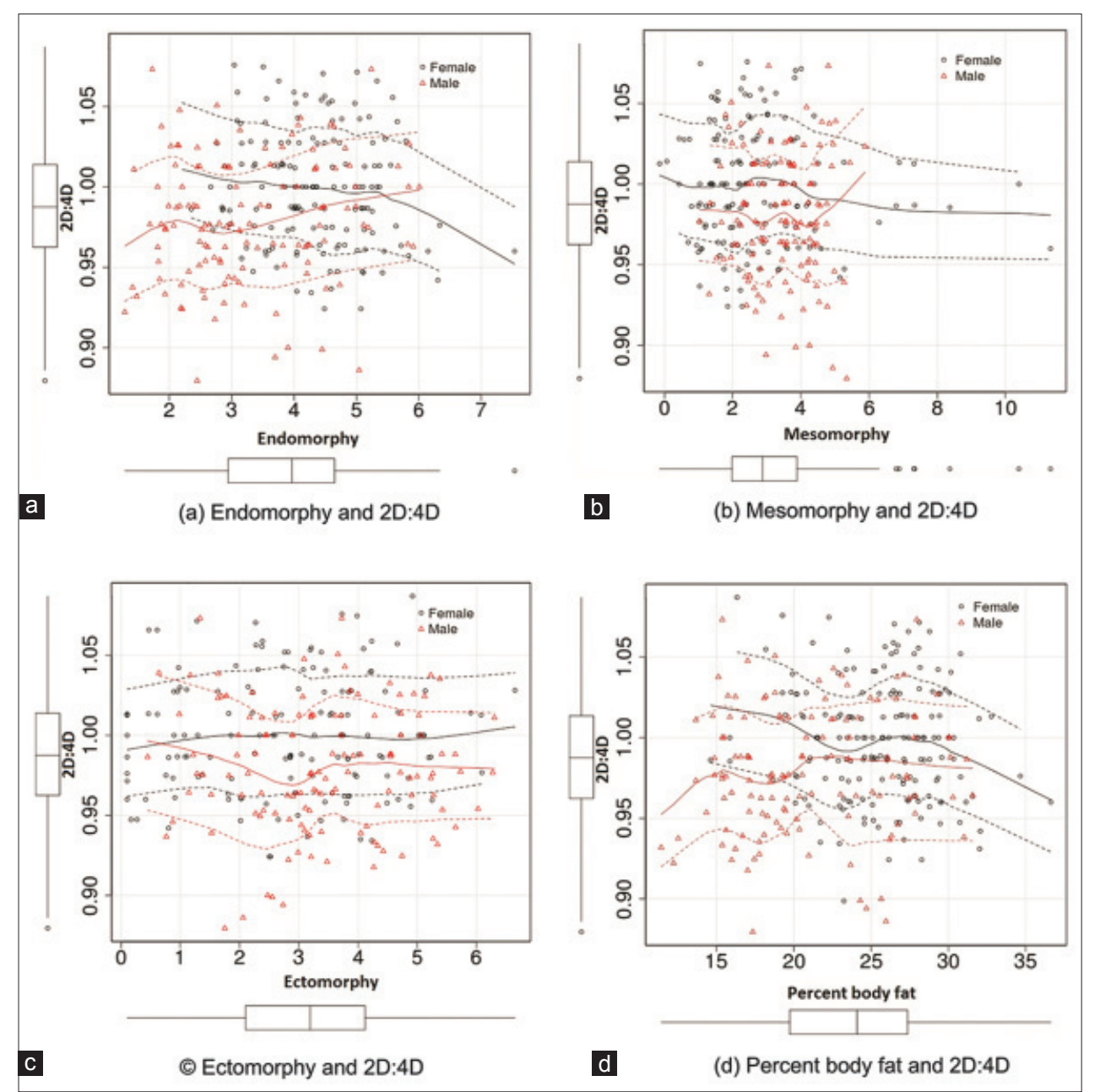

Figure 1: The scatter plots with fitted lines for estimated means with marginal box plots among men and women, (a) endomorphy with 2D:4D, (b) mesomorphy with 2D:4D, (c) ectomorphy with 2D:4D, (d) percent body fat with 2D:4D

Further, comprehensive three-dimensional scatter plot in terms of percent body fat, waist-hip ratio and 2D:4D (Figure 2) showed that the body fat increased with increase in 2D:4D among men, irrespective of any particular body site. However, women demonstrated increase in waist-hip ratio with increase in $2 \mathrm{D}: 4 \mathrm{D}$, revealing significant fat deposition at the waist-hip region.

\section{DISCUSSION}

To our knowledge, this is the first study to explore inter as well as intra-gender differences in 2D:4D and its relationship with body composition indicators among young Indian population. Study examined the second and fourth finger length ratio among young adults with an attempt to explore 


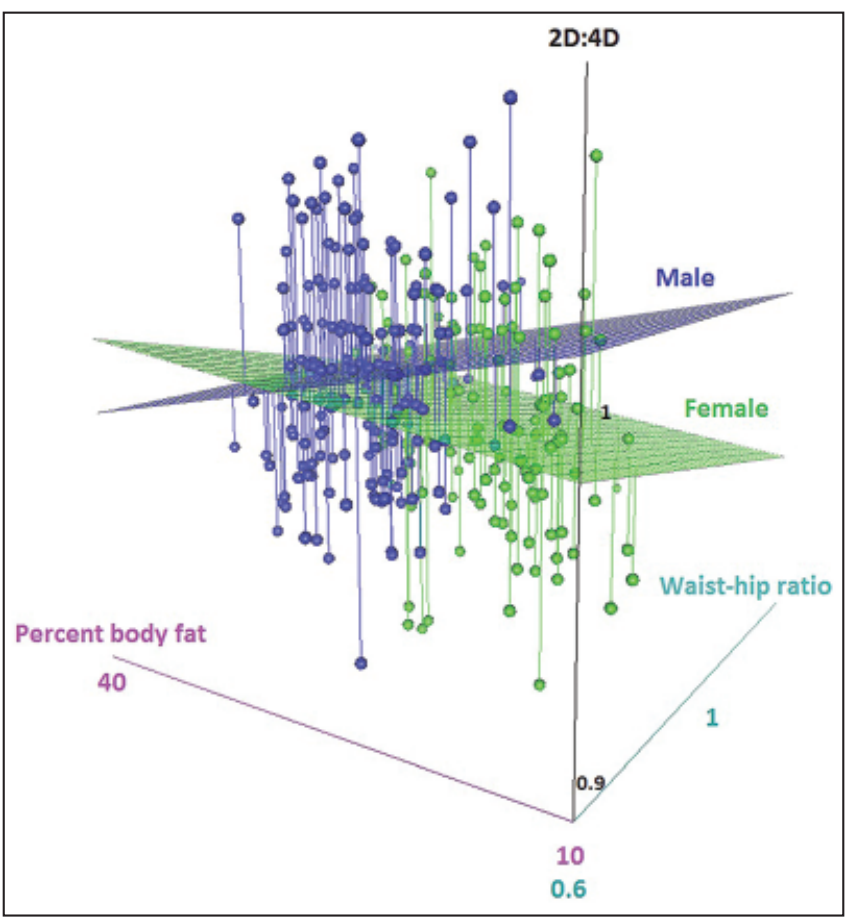

Figure 2: Three-dimensional scatter plot of percent body fat, waist-hip ratio and 2D:4D among men (blue) and women (green). Plane for men (blue) shows the leaning toward higher percent body fat with higher 2D:4D. Plane for women (green) shows the tendency towards higher waist-hip ratio

its relation to various body composition indicators and body somatotyping. Study reiterated the findings of differential anthropometric body composition indicators and 2D:4D between men and women. Present work revealed that body composition indicators did not differ between 2D:4D less than or more than one among both men and women. Further, the study reports that women demonstrated endomorphic characteristics (relative fatness) as well as diminished musculoskeletal robustness with increase in 2D:4D.

The results of the present study suggest that 2D:4D and anthropometric body composition indicators are significantly different between men and women. ${ }^{4}$ As far as morphological characteristics are concerned, men had higher mesomorphy component, followed by ectomorphy and endomorphy, thus structural features towards dominant mesomorphy can be considered as male type features. ${ }^{21}$ Among women, endomorphy component was dominant followed by mesomorphy and later ectomorphy. In the present study, percent body fat in women was significantly higher than that of men which is in concordance with other related studies. ${ }^{21,22}$ The $2 \mathrm{D}: 4 \mathrm{D}$, a determinant of sexual dimorphism, was significantly different between men and women with lower ratio more linked with men and higher ratio with women. ${ }^{23-25}$ However, ectomorphic characteristics remained uniform with the range of $2 \mathrm{D}: 4 \mathrm{D}$. Current study observed that musculoskeletal robustness (mesomorphy score) among majority of men was within the range of 2-5. Also with increase in $2 \mathrm{D}: 4 \mathrm{D}$, the relative fatness showed an increasing trend.

Among women in the study population, with decrease in 2D:4D, musculoskeletal robustness as well as relative fatness were found increasing, which may be attributed to increased tendency of peripheral fat accumulation. ${ }^{26}$ Interestingly, decrease in 2D:4D was found related with increased percent body fat among women, further supporting the above statement. Among men, with increase in 2D:4D, percent body fat was increasing till $20 \%$ and further remained stable with the range of 2D:4D (Figure 1). This implies that there is no strong association between 2D:4D and anthropometric body composition indicators among men. ${ }^{27}$ Previous studies observed limited/no association between 2D:4D and any anthropometric measure among women. ${ }^{10,27}$ However, present study indicated some trend observations with lower 2D:4D ratio's association with the male type pattern of anthropometric indicators. This result may be possibly due to difference in ethnicity, which needs to be further explored among different population with larger sample size.

We tried to investigate the hypothesized difference in body composition indicators with 2D:4D more or less than one among each groups. However, only the percent body fat was found lower in men with 2D:4D less than one, although no significant difference in men with 2D:4D more than one was observed. In case of women, height, weight, arm circumference and BMI were statistically different, although inter-gender difference in BMI did not exist. Fink et al. also reported positive relation of BMI with digit ratio among females. ${ }^{4}$ The results corroborate with a longitudinal study on larger population, wherein the investigators concluded that 2D:4D is not strongly associated with adult anthropometric measures, including those of adiposity. ${ }^{27}$ The three-dimensional plot with percent body fat, waisthip ratio and 2D:4D ratios elucidates that men are more lateralized toward having higher percent body fat (Figure 2). In case of women however, they are more susceptible to increase in waist-hip ratio, which is moderately inverse to the results of the study by Fink et al. ${ }^{4}$

Although both genders are differentiated on the basis of anthropometric characteristics and 2D:4D, the present study lead to the understanding that digit ratio may have a modest role in understanding the body composition indicators in terms of association between lower 2D:4D with male type pattern of anthropometric indicators even among young women.

Limitation of the study was use of tracing method for the $2 \mathrm{D}$ and $4 \mathrm{D}$ length measurements, which may not 
accurately measure lengths of $2 \mathrm{D}$ and $4 \mathrm{D}$, however it is one of the methods of finger length measurement. As it is the ratio measurement, inaccuracies in the finger length may not have influenced the study results. Strength of the study was understanding the body composition indicators and body typing in relation to 2D:4D. Further, this approach expresses the relationship of $2 \mathrm{D}: 4 \mathrm{D}$ with body composition as well as inter-gender distinction among young Indian population.

\section{CONCLUSION}

The present study reiterated the findings of differential anthropometric body composition indicators and 2D:4D between men and women. Further, among men, anthropometric measurements did not differ with 2D:4D of more or less than one. Lower 2D:4D may seem to have modest association with male type measures of body composition among women. This study is an attempt exploring the relation between finger length ratio and body composition indicators among Indian population. Further studies with variable population may help in determining 2D:4D as a marker of obesity and associated lifestyle disorders.

\section{ACKNOWLEDGEMENT}

This study was funded by the Institutional intramural support. The authors are grateful to the staff of the department for assisting in participant recruitment, data collection and lab management. The authors also acknowledge the whole-hearted participation of the volunteers in the study.

\section{REFERENCES}

1. Phelps VR. Relative index finger length as a sex-influenced trait in man. American Journal of Human Genetics 1952; 4:72-89.

2. Halil M, Gurel El, Kuyumcu ME, Karaismailoglu S, Yesil Y, Ozturk ZA, et al. Digit (2D:4D) ratio is associated with muscle mass (MM) and strength (MS) in older adults: Possible effect of in utero androgen exposure. Archives of Gerontology and Geriatrics 2013; 56(2):358-363.

3. Peeters MW, Van Aken K and Claessens AL. The Left Hand Second to Fourth Digit Ratio (2D:4D) Is Not Related to Any Physical Fitness Component in Adolescent Girls. PLoS ONE 2013; 8(4):e59766.

4. Fink B, Neave N and Manning JT. Second to fourth digit ratio, body mass index, waist-to-hip ratio, and waist-to-chest ratio: Their relationships in heterosexual men and women. Annals of Human Biology 2003; 30(6):728-738.

5. Manning JT. Digit Ratio: A pointer to fertility, behavior, and health. New Brunswick, New Jersey: Rutgers University Press, 2002.

6. Giffin NA, Kennedy RM, Jones ME and Barber CA. Varsity athletes have lower 2D:4D ratios than other university students. Journal of Sports Sciences 2012; 30:135-138.

7. Longman D, Stock JT and Wells JC. Digit ratio (2D:4D) and rowing ergometer performance in males and females. American Journal of Physical Anthropology 2011; 144:337-341.

8. Van Anders SM. Grip strength and digit ratios are not correlated in women. American Journal of Human Biology 2007; 19(3):437-439.

9. Zhao D, Li B, Yu K and Zheng L. Digit ratio (2D:4D) and handgrip strength in subjects of Han ethnicity: impact of sex and age. American Journal of Physical Anthropology 2012; 149(2):266-271.

10. Fink B, Manning JT and Neave N. The 2nd-4th digit ratio (2D:4D) and neck circumference: implications for risk factors in coronary heart disease. International Journal of Obesity 2006; 30(4):711-714.

11. McIntyre MH, Lipson SF and Ellison PT. Effects of developmental and adult androgens on male abdominal adiposity. American Journal of Human Biology 2003; 15(5):662-666.

12. Geetha KN, Patel SC, Chavan LN and Charushila S. Hand digit ratio (2D:4D) and sexual dimorphism in different age groups. Journal of Clinical Research Letters 2012; 3(1):1618.

13. Manning JT, Henzi $P$, Venkatramana $P$, Martin $S$ and Singh D. Second to fourth digit ratio: ethnic differences and family size in English, Indian and South African populations. Annals of Human Biology 2003; 30(5):579-588.

14. Divakaran A, Narayanaswamy JC, Kalmady SV, Narayan V, Rao NP and Venkatasubramanian G. Family history correlates of digit ratio abnormalities in schizophrenia. Indian Journal of Psychological Medicine 2012; 34(4):355-359.

15. Kalmady SV, Agarwal SM, Shivakumar V, Jose D, Venkatasubramanian G and Reddy YC. Revisiting Geschwind's hypothesis on brain lateralisation: A functional MRI study of digit ratio (2D:4D) and sex interaction effects on spatial working memory. Laterality 2013; 18(5):625-640.

16. Carter JEL. The Heath-Carter Anthropometric Somatotype: Instruction Manual. San Diego, USA, 1990.

17. http://goulding.ws/somatotype/[http://www.somatotype.org]. South Australia: Sweat Technologies; (c) 2010. http://goulding. ws/somatotype/. Retrieved 11/07/2014, 11,00hrs.

18. Siri, HE. Body composition from fluid space and density. In: Brozek, J., Hanschel, A. (Eds.), Techniques for measuring body composition. National Academy of Science, Washington, DC, 1961:223-244.

19. Du Bois D and Du Bois EF. A formula to estimate the approximate surface area if height and weight be known. 1916. Nutrition 1989; 5(5):303-311; discussion 312-313.

20. Bergman RN, Stefanovski D, Buchanan TA, Sumner AE, Reynolds JC, Sebring NG, et al. A Better Index of Body Adiposity. Obesity (Silver Spring) 2011; 19(5):1083-1089.

21. Camhi SM, Bray GA, Bouchard C, Greenway FL, Johnson WD, Newton RL et al. The relationship of waist circumference and BMI to visceral, subcutaneous, and total body fat: sex and race differences. Obesity 2011; 19:402-408.

22. Nicolaou M, Kunst AE, Busschers WB, van Valkengoed IG, Dijkshoorn $\mathrm{H}$, Boateng $\mathrm{L}$, et al. Differences in Body Fat Distribution Play a Role in the Lower Levels of Elevated Fasting Glucose amongst Ghanaian Migrant Women Compared to Men. PLoS ONE 2013; 8(6):e66516.

23. Hisasue S-I, Sasaki S, Tsukamoto T and Horie S. The relationship between second-to-fourth digit ratio and female gender identity. The Journal of Sexual Medicine 2012; 9(11):2903-2910. 
24. Kalichman L, Zorina D, Batsevich V and Kobyliansky E. 2D:4D finger length ratio in the Chuvashian population. HOMO-Journal of Comparative Human Biology 2013; 64(3):233-240.

25. Lippa RA. Are 2D:4D finger-length ratios related to sexual orientation? Yes for men, no for women. Journal of Personality and Social Psychology 2003; 85(1):179-188.

26. Wells JCK. Sexual dimorphism of body composition.
Best Practice \& Research: Clinical Endocrinology 2007; 21(3):415-430.

27. Muller DC, Manning JT, Hopper JL, English DR, Giles GG and Severi G. No strong association between second to fourth digit ratio (2D:4D) and adult anthropometric measures with emphasis on adiposity. Annals of Human Biology 2013; 40(2):201-204.

\footnotetext{
Authors Contribution:

JM - Designed the study, performed the experiment, analysed the data, drafted the manuscript, \& reviewed the manuscript; BSB - Performed the experiment, analysed the data, reviewed the manuscript.

Source of Support: Institutional support, Conflict of Interest: None declared
} 